\title{
40/42Gy in 13 Fractions: A Safe Dose for the Brachial Plexus
}

\author{
Gabriela Studer $^{1 *}$, David Norbert Stocker ${ }^{2}$, Karl Ferdinand Loewenich ${ }^{1}$ and Christoph Glanzmann ${ }^{1}$ \\ ${ }^{1}$ Department of Radiation Oncology, University Hospital Zurich, Raemistrasse 100, 8091 Zurich, Switzerland \\ ${ }^{2}$ Grundstrasse 61, 6430 Schwyz, $\mathrm{CH}$, Switzerland
}

*Corresponding author: Gabriela Studer, Department of Radiation Oncology, University Hospital Zurich Raemistrasse 1008091 Zurich CH - Switzerland, Tel: 4144 25539 31; Fax: +41 4425545 47; E-mail: gabriela.studer@usz.ch

Received date: Feb 19, 2014, Accepted date: March 24, 2014, Published date: March 31, 2014

Copyright: ( 2014 Studer, et al. This is an open-access article distributed under the terms of the Creative Commons Attribution License, which permits unrestricted use, distribution, and reproduction in any medium, provided the original author and source are credited.

\begin{abstract}
Aims: The use of hypo fractionated irradiation of the whole breast has regained much interest after the publication of the results of large randomized trials showing equivalent results as using standard fractionation (START A and B, randomized START pilot trials, Canadian trial). Due to the relatively low numbers of patients treated with hypofractionation to the supraclavicular \pm axillary $(\mathrm{S} / \mathrm{A})$ region, the question of the brachial plexus tolerance continues to be discussed.
\end{abstract}

Aim of this work was to assess the high grade long term tolerance of the brachial plexus in our patients treated with $13 \times 3.3 \mathrm{~Gy}$ to the S/A lymph nodes, in order to contribute to the question of plexus tolerance.

Materials and Methods: Between 1967 and 1977, 130 female breast cancer patients underwent postoperative hypo fractionated radiotherapy at the University Hospital Zurich. The most used schedule was $13 x 3.3 \mathrm{~Gy}$ midline dose, $3 x /$ week $(n=124)$ to the $S / A$ region applied by equally rated antero-posterior/postero-anterior portals. A first assessment of the cohort was performed in 1994, which has been updated in December 2013. Patients with a follow up period $<5$ years or loco-regional disease have been excluded in 1994 ( $n=4$, all without plexopathy). Pre-radiation surgery consisted of radical mastectomy in $98 \%$ and breast conserving operation in $2 \%$ of all patients, including axillary dissection. Pathological stage was pT1/2/3/4 in $28 / 58 / 10 / 4 \%$; with pNO/pN+ in $57 / 43 \%$. The mean/median follow up time of the cohort was 28.1/26.6 years (range, $7.2-44.8$ ).

Results: One grade 2 brachial plexus neuropathy was observed.

Conclusion: The long term follow up in our patients corroborates the hypothesis of a total mid plane dose to the S/A region between $40-42 \mathrm{~Gy}$ in 13 fractions being comparably safe as $25 \mathrm{x} 2.0 \mathrm{~Gy}$ to $50 \mathrm{~Gy}$.

Keywords: BPN; Brachial plexus tolerance; Hypo fractionation; Radiation-induced brachial plexus neuropathy; Radiation tolerance

\section{Introduction}

The use of hypo fractionated irradiation of the whole breast has regained much interest after the publication of the results of large randomized trials showing equivalent results as when using standard fractionation (START A and START B, Canadian trial, randomized pilot trial for the START trial [1-6]. Based on these results from $>7000$ patients, the national institute for health and clinical excellence (NICE) has included the hypo fractionated regime with $40 \mathrm{~Gy} / 3$ weeks in 15 fractions into its national guidelines [7], (http:// www.nice.org.uk).

Some centers use hypo fractionation since many years, resulting in a large, albeit retrospective experience with these regimes [8-11].

History of the use of hypo fractionated radiation schedules for the breast at our institution.

During the period between 1967 and 1977, two regimes were used at our centre for curative irradiation of the whole breast or the chest wall: $5 \mathrm{x} 2.0 \mathrm{~Gy}$ per week to $50 \mathrm{~Gy}$ ( \pm boost to $60-66 \mathrm{~Gy}$ ), or -in most cases- $3 \times 3.3 \mathrm{~Gy}$ per week to $42.9 \mathrm{~Gy}$. For logistic reasons, hypo fractionation was preferred in nearly all ambulatory patients with curative postoperative (post-mastectomy and breast conserving surgery) irradiation for breast cancer. In that period, in most patients the regional lymph nodes have also been included in the elective treatment volume. Since the opening of our department decades ago, life-long follow up of all patients used to be the standard practice; therefore nearly all irradiated patients had regular physical check-ups in our department, however since approximately 1985, most patients were no longer followed by physical examination at our department but regularly contacted by phone and/or by collecting follow up information with help of questionnaires.

After the publication of the results of the large fractionation study of the British Institute of Radiology (BIR) in 1978 [12] (showing inferiority of hypo fractionation as compared to norm fractionation schedules), hypo fractionation has, as a consequence, been abandoned in the curative treatment setting at University Hospital Zurich (USZ).

In 1993, Olsen et al. reported a relatively high rate of lesions of the brachial plexus after standard irradiation with 50Gy [13]. Motivated by that publication, in 1994, we reviewed the medical charts of all our loco-regionally controlled breast cancer patients treated with curative postoperative hypo fractionated radiation between 1967 and 1977, with focus on late term tolerance of the brachial plexus following 
Page 2 of 8

3.3Gy per fraction to the axillary \pm supraclavicular (A/S) lymph nodes. Our first evaluation of the here presented cohort back in 1994 included a physical examination with focus on BPN in 25/130 patients, with a mean follow up of 18 years (5-36) post radiation; 56 additional patients could be contacted for a detailed phone call interview specifically focusing signs and symptoms of substantial BPN. For the remaining 49 patients (loss of follow up or death), specific information was extracted by reviewing their records: in $89 \%$ of the cohort there was no clinical sign of brachial plexus alteration. 13 women (10\%) treated with $13 \mathrm{x} 3.3 \mathrm{~Gy}$ described subtle neurological symptoms like pain in the arm and mild hypaesthesia (starting $\sim 1-17$ years post treatment, mean time to appearance not exactly known as symptoms may have been mild and therefore not always recognized/indicated by patients), which were not clinically relevant (grade $1 \mathrm{BPN}$, see grading below); objectively, a mild subcutaneous induration of the irradiated region was observed in those women. Of importance in this context is the fact that most patients treated in that historic era had undergone Halsted radical mastectomy and radical axillary lymphonodectomy.

Pleasingly, only one mild subjective and objectively not limiting grade 2 brachial plexus neuropathy (BPN) in one of the clinically assessed patient treated with $13 \times 3.3 \mathrm{~Gy}$ was seen at that time.

\section{Aim of this work}

Due to the relatively low number of patients treated with hypo fractionated radiotherapy to the S/A region [14-19], the question of the brachial plexus tolerance continues to be discussed. In December 2013, we performed an update of the above described hypofractionation cohort, at a mean/median follow up time of meanwhile 28.1/26.6 years (7.2-44.8), aiming to re-assess the late term tolerance of the brachial plexus.

\section{Methods and Materials}

\section{Patients}

In December 2013, an update of the above described cohort was performed motivated by the again increasing interest in hypo fractionated radiation schedules nowadays.

The medical records of the eligible 130 patients were still available and were reviewed, in order to assess the long term tolerance of the brachial plexus following our 1967 to 1977, predominantly used hypofractionation schedule with $13 \mathrm{x}(12-15 \mathrm{x}) 3.3 \mathrm{~Gy}$ in 3 fractions per week to the breast and S/A lymph nodes, (Table 1).

\begin{tabular}{|l|l|}
\hline Parameters & Hypofractionation Cohort \\
\hline number of patients & 130 \\
\hline treatment interval & $1967-1977$ \\
\hline mean ageat radiation (range) & $54(27-77)$ years \\
\hline at first analysis, 1994 & $73(50-97)$ years \\
\hline at last analysis, 2011 & $76(50-98)$ years \\
\hline T stage pT1/2/3/4 & $28 / 58 / 10 / 4 \%$ \\
\hline N stagepN+/pN0 & $43 / 57 \%$ \\
\hline follow up (FU) time & \\
\hline
\end{tabular}

\begin{tabular}{|c|c|}
\hline mean / median (range), in years: & \\
\hline all & $28.1 / 26.6(7.2-43.6)$ \\
\hline lost of FU cohort (death, moved; 33\%) & $18.7 / 18.2(7.2-27)$ * \\
\hline known dead of disease (DOD, $2 \%$ ) & at 18.5 and 25.6 years \\
\hline INED (33\%) & 30.8 / $29.5(20-38.9)$ \\
\hline ANED $(63 \%)$ & $27.1 / 23.7(7.2-43.6)$ \\
\hline ANED, still alive $(06 / 2011,15 \%)$ & 39.6 / $40.6(38.3-42.5)$ \\
\hline $6-10$ years FU & $7 \%$ \\
\hline$>10-20$ years $\mathrm{FU}$ & $28 \%$ \\
\hline$>20-30$ years $\mathrm{FU}$ & $59 \%$ \\
\hline$>30$ years $\mathrm{FU}$ & $6 \%$ \\
\hline \multicolumn{2}{|l|}{ previous breast surgery } \\
\hline (mostly radical) mastectomy & $98 \%$ \\
\hline breast conserving & $2 \%$ \\
\hline \multicolumn{2}{|l|}{ hypofractionation schedules, 3f/w } \\
\hline \multicolumn{2}{|l|}{$[\mathrm{BE} \Delta 2 \Gamma \Psi, \alpha / \beta=2 / \alpha / \beta=3,5 \varphi / \omega]$} \\
\hline $13 \times 3.3 G y=42.9 G y[56 / 54 G y]$ & 124 \\
\hline $12 x 3.3 \mathrm{~Gy}=39.6 \mathrm{~Gy}[52 / 50 \mathrm{~Gy}]$ & 2 \\
\hline $15 x 3.3 G y=49.5 G y[66 / 62 G y]$ & 2 \\
\hline $14 \times 3.3 \mathrm{~Gy}=46.2 \mathrm{~Gy}[61 / 58 \mathrm{~Gy}]$ & 1 \\
\hline $14 \times 3.5 \mathrm{~Gy}=49.0 \mathrm{~Gy}[68 / 64 \mathrm{~Gy}]$ & 1 \\
\hline \multicolumn{2}{|l|}{ allive with known disease } \\
\hline at first analysis, 1994 & 0,1 \\
\hline at last analysis, 2011 & 2,5 \\
\hline
\end{tabular}

Table 1: Characteristics of the assessed hypofractionation cohort $(\mathrm{n}=130)$.

* 3 patients were alive with disease when last time seen, all others ANED; Loss of follow up was in most patients due to emigration to other countries; ANED: Alive and No Evidence of Disease when last time seen; AD: Alive with Disease when last time seen; DOD: Died of Disease; INED: Inter-currently died, No Evidence of Disease

None of the historic patient cohort underwent chemotherapy, and breast conserving surgery was performed in only $2 \%$. In all patients the A/S lymphatic pathway was included into the radiation volume. Exclusion criteria as defined for the first assessment in 1994 were: (a) follow up period information of $<5$ years, and/or (b) local or regional recurrence. Four (4/134) loco-regionally disease free patients were excluded due to a too short follow up time; all four patients had no signs of BPN at last contact. From all of the remaining 130 patients any follow up information (i.e. clinical examination at our institution and/or information by phone, letters, charts) was available; in $78 \%$ of the cohort regular physical examinations at our institution for $>5$ years was performed. Since approximately 1985, most patients were no longer regularly physically examined at our department, but were 
annually contacted by phone and/or questionnaires during the first 10 years and thereafter biannually. In addition, follow up information of all patients used to be regularly collected based on follow up letters of, or phone calls to caring family doctors and gynaecologists.

\section{Methods}

Definition of the used grading for PBN: In 1994, the following grading system has been defined and was used since to assess BPN in our patients:

\section{Grade 0: no symptoms}

Grade 1: anamnestic mild arm pain or weakness, without impact on daily life, plus the following clinical symptoms: dysaesthesia, hypo-/ areflexia

Grade 2: paresis, functionally nonlimiting (plus all grade 1 symptoms)

Grade 3: disabling paresis or paralysis, with consecutive limitations in daily life

\section{Radiation techniques}

The used hypofractionation schedules are shown in Table 1.

The estimated Biological Effective Dose $(B E D,=D(1+d /(\alpha / \beta))$ to the used hypofactionated schedules for normofractionation $(2 \mathrm{~Gy} /$ day, 5 fractions (f)/week) is calculated for an alpha/beta ratio of $2 \mathrm{~Gy}$ and $3 \mathrm{~Gy}$ for the brachial plexus.

The A/S region radiation therapy has been performed by opposing antero-posterior (ap-pa) fields with equal weight and a midline dose of 39-49Gy in 3 fractions/week. Matching between ap-pa A/S and oblique opposed breast tangential fields was performed using tilt gantry and table rotation to compensate for beam divergence of the cobalt 60 machine as used in that period. Calculation of midline dose was then performed by manual calculation using depth dose tables. Source skin distance was $55-90 \mathrm{~cm}$ (90 cm in most cases). An example of an old simulation film (1972) of a supraclavicular/axillary radiation field is shown in Figure 1.

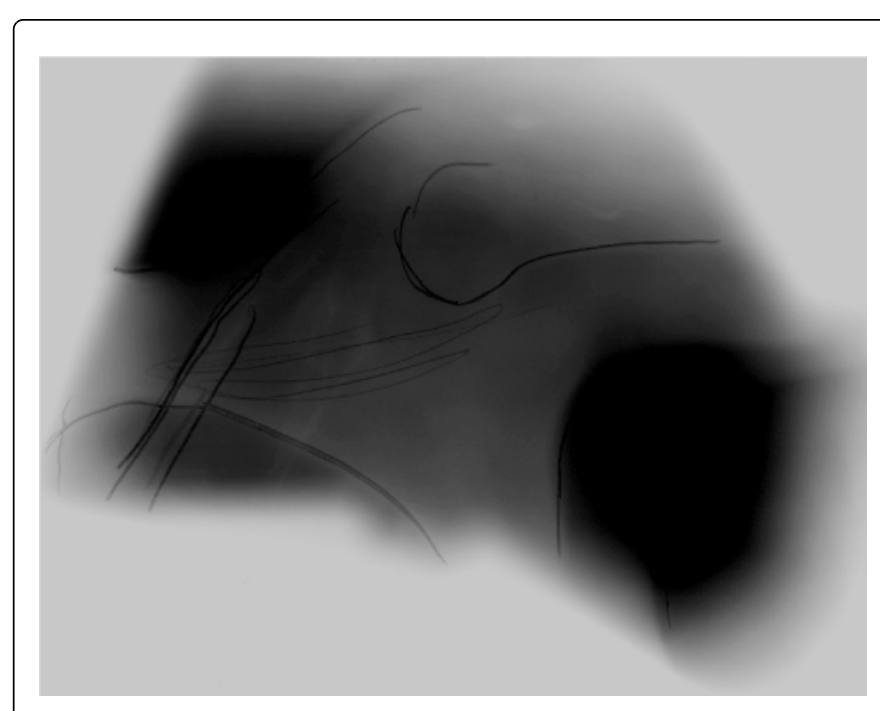

Figure 1: Simulation film of a supraclavicular/axillary radiation field (1972).

Two of the authors (KL and CG) performed recalculations of the dose distribution in 3 patients by using a CT calculation program for Cobalt 60. Recalculations were based on a model for a Siemens 'Gammatron R' cobalt unit (the machine that has been used for treatment of this patient cohort; model provided by Dr Richard Lösch, Klinikum St. Marien, Augsburg, Germany) in the Pinnacle [30] version 8.0 treatment planning system (TPS, Philips Healthcare, Andover MA).

Figure 2 shows dose distributions to the brachial plexus using different set ups as resulting from these recalculations; Figure 3 shows related dose volume histograms (DVHs) of the arm plexus using different treatment set ups (a-d). 
Citation: Studer G, Stocker DN, Loewenich KF, Glanzmann C (2014) 40/42Gy in 13 Fractions: A Safe Dose for the Brachial Plexus. J Nucl Med Radiat Ther 5: 168. doi:10.4172/2155-9619.1000168

Page 4 of 8

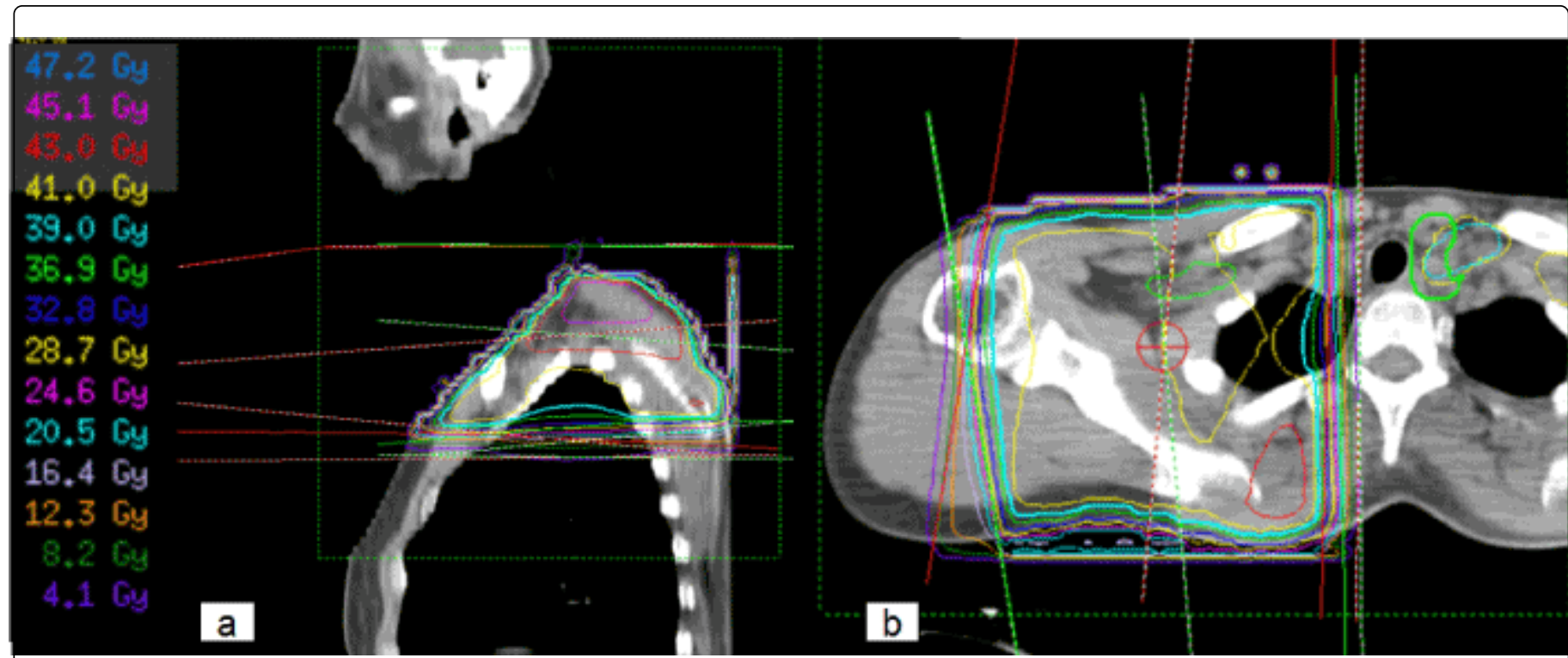

Figure 2: Dose distribution. a) Sagittal view of the dose distribution of opposed 6MV fields (midline dose) with $100 \mathrm{~cm}$ source - isocenter distance b) Axial view of the dose distribution of opposed 6MV fields (mid plane dose) with $100 \mathrm{~cm}$ source -isocenter distance.

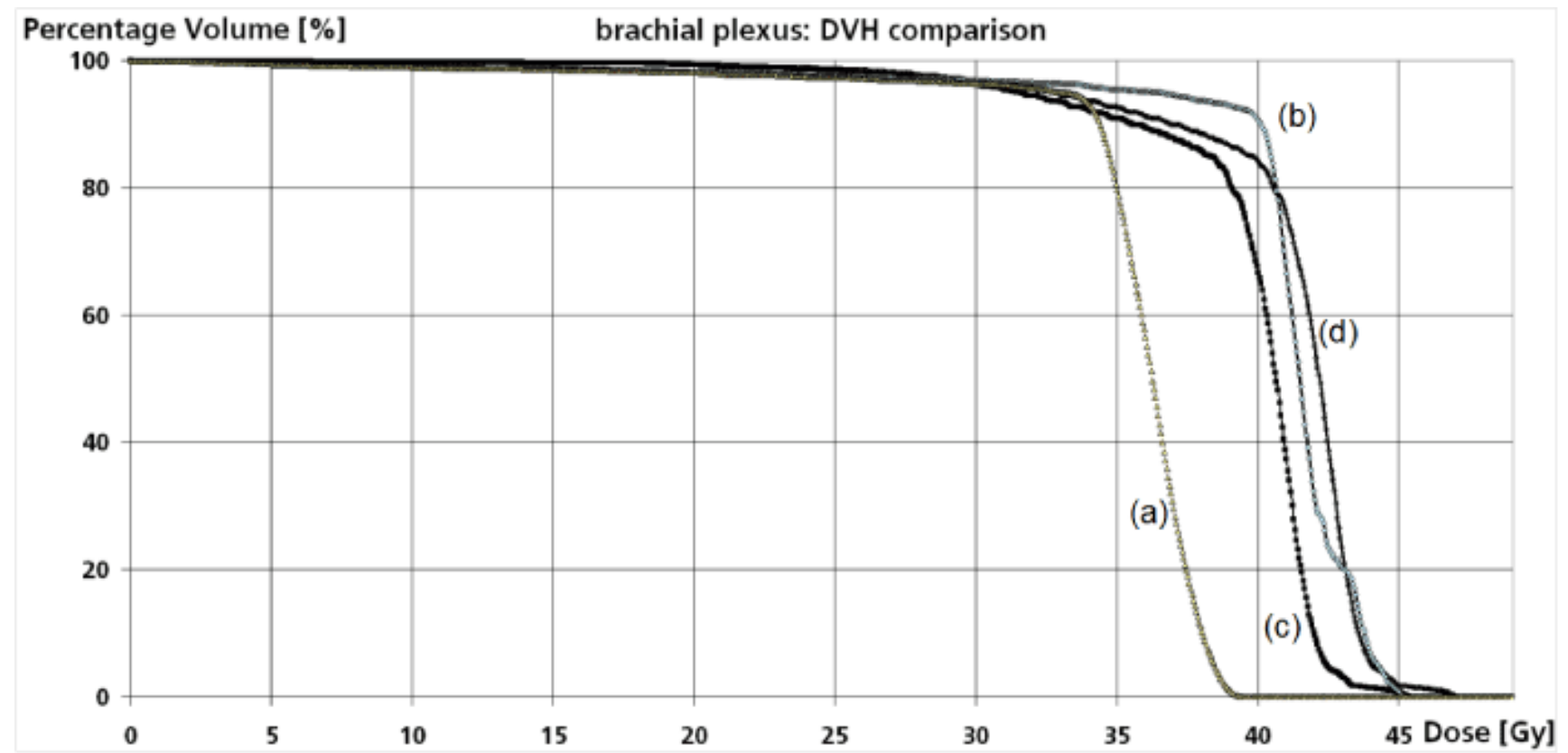

(a): $6 \mathrm{MV}$ ap beam, $13 \times 3.2 \mathrm{~Gy}$ (maximum of build up)

(b): $6 \mathrm{MV}$ ap-pa opposed beams, midline dose, equally weighted $13 \times 3.2 \mathrm{~Gy}$

(c): Co60 ap-pa opposed beams, midline dose, equal weight, 13x 3.168Gy

(d): Co60 ap-pa opposed beams, midline dose, equal weight, 13x 3.3Gy

Figure 3: Dose Volume Histograms (DVH) of the arm plexus for different treatment set up, a) 6MV ap beam, 13x3.2Gy (max of build-up), b) $6 \mathrm{MV}$ ap-pa opposed beams, midline dose, equally weighted $13 \times 3.2 \mathrm{~Gy}$, c) Co60 ap-pa opposed beams, midline dose, equally weighted $13 \times 3.168 \mathrm{~Gy}, \mathrm{~d})$ Co60 ap-pa opposed beams, midline dose, equally weighted 13x3.3Gy. 
Page 5 of 8

\section{Statistics}

StatView ${ }^{\bullet}$ (Version 4.5) with its integrated calculation programwas used as data base andfor related calculation of follow up (no further statistics were calculated due to only one event).

\section{Results}

Follow up characteristics of the assessed cohort are listed in Table 2 and Figure 4.

\begin{tabular}{|l|l|l|l|}
\hline $\begin{array}{l}\text { Follow Up } \\
(\mathrm{FU})\end{array}$ & $\begin{array}{l}\text { clinical FU at } \\
\text { USZ }\end{array}$ & $\begin{array}{l}\text { FU information from letters/charts/ } \\
\text { calls }\end{array}$ & known death \\
\hline years $(\mathrm{y})$ & $\%$ & $\begin{array}{l}\text { letters/charts/calls +/- clinical FU, } \\
\%\end{array}$ & $\%$ \\
\hline$<5 y$ & 22 & 0 & 0 \\
\hline$>1=5 y$ & 78 & 100 & $16 \%$ \\
\hline $5-10 y$ & 19 & 7 & 0 \\
\hline$>10-15 y$ & 23 & 9 & 0 \\
\hline
\end{tabular}

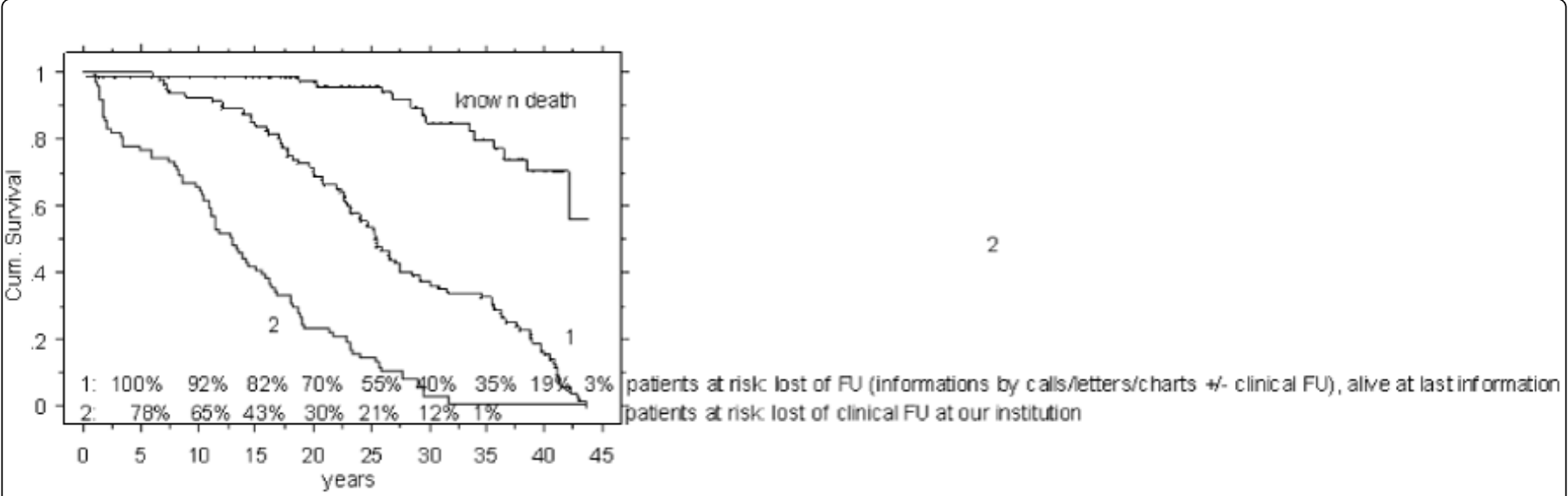

Figure 4: Kaplan Meier follow up curves analysed according to patients followed by information from charts, letters, phone calls $+/$ - clinical FU at our department (1), isolated depicture of the clinical follow up at our department (2) and overall survival based on confirmed informationaboutpatients'death.

The above mentioned patient with grade 2 BPN as stated in1994 (see 'introduction'), was clinically examined for the last time in 11/2013,nearly 45 years after radiation therapy: this lady presents with a still persisting grade 1-2 BPN, no pain, being a content and active and indicating no additional complaints. Her history was the following: in the age of 40 this patient underwent breast conserving surgery for a T1N0 breast tumor in 1969, followed by hypo fractionated radiation with $13 \mathrm{x} 3.3 \mathrm{~Gy}$ to the residual breast and the axillary region uses an ap-pa field technique, and to the supraclavicular region using an anterior field (calculated to $3 \mathrm{~cm}$ depth). The arm plexus was most likely in the region of this field overlap. In 1983, 14 years later, the patient experienced a local recurrence of her disease and underwent a mastectomy and axillary revision. Grade 2 PBN with some degree of paresis of the arm was diagnosed in 1994. The patient kept on being able to work as a secretary performing mostly typing duties. As this activity requires substantial fine motor skills, the lesion was then classified asa grade 2 BPN.

\begin{tabular}{|l|l|l|l|}
\hline$>15-20 y$ & 15 & 19 & 2 \\
\hline$>20-25 y$ & 9 & 35 & 2 \\
\hline$>25-30 y$ & 10 & 24 & 5 \\
\hline$>30 y$ & 2 & 6 & 7 \\
\hline
\end{tabular}

Table 2: Follow up characteristics of the own cohort.

Partial hypaesthesia of the upper arm was a frequently seen symptom, but was also recorded in the charts of many patients who had no S/A radiation, and may be related to the substantially more radical operation techniques (Halsted) used in the past. A frequent finding was a fat atrophy in the shoulder region. In addition, in one patient a subtle weakness of the arm was described, which, however was not limiting in the daily routine work (grade 1 , diagnosed $>16$ years post treatment).

No grade 3BPN events developed in our cohort with a mean observation time of 28 years.

\section{Discussion}

The aim of this work was to assess long term high grade BPN following hypo fractionated radiation to the arm plexus.

No grade 3/4 PBN was observed in the assessed cohort of patients treated with hypo fractionated radiation therapy using 3.3Gy in mostly 13 fractions.

The weakness of the study is its retrospective approach, and the lack of a specific investigation questionnaire regarding the brachial plexus function in order to detect milder BPN symptoms. More subtle degrees of BPN may have been missed by this method, although probably of limited relevance in daily life, and difficult to clinically differentiate from possible long term sequels after radical mastectomy, as performed in most patients of this historic cohort. Of importance to note in this context is that neuropathic shoulder arm symptoms and/or signs are common following mastectomy ( \pm chemotherapy) only: in a prospective study on 100 surgery-only patients (50 patients 
Page 6 of 8

with modified radical mastectomy, 50 patients with wide local excision and axillary clearance treated between 2004-2006), 60\% of patients reported one or more symptoms: numbness and pain in $39 \%$ each [20]. Arm symptoms were also reported most commonly during the first year after surgery \pm radiotherapy to the breast by Liljegren et al in their randomized trial on 381 patients, and a further reduction was noted over the subsequent years by around $40-50 \%$ [21]. In the randomized ALMANAC trial $>28 \%$ of 405 patients reported at least one arm symptom by 18 months post axillary surgery [22]. Engel et al. assessed 5-year quality of life data of 1131 patients in a prospective cohort study and found new and remained arm problems in $6 \%$ and $34 \%$ at year $4-5$, respectively [23].

In the large Manchester analysis of $>2000$ cases treated with 40Gy/ 15 fractions in 3 weeks, the same methodology was used to assess the follow up information (review of the case notes of all patients/ contacting GPs and/or surgeons for information on patients who had been lost to follow-up or discharged) [24].

The focus of our analysis was on clinically relevant BPN (grade $\geq 2$ ), which is hardly to miss by patients and caring physicians. Grade $>/=2$ symptoms are expected to be spontaneously reported by patients and related symptoms are evident at regular physical check-up, thus the presented study results are considered reliable.

\begin{tabular}{|c|c|c|c|c|c|c|c|c|c|c|}
\hline FRACTIONATION & $\begin{array}{l}\text { Author } \\
\text { [ref] }\end{array}$ & Year & $\begin{array}{l}\text { Treatment } \\
\text { Interval }\end{array}$ & $\begin{array}{l}\text { Follow up } \\
\text { years } \\
\text { (range) }\end{array}$ & $\mathrm{n}$ pat & $\begin{array}{l}\text { Dose/Session } \\
\text { (Gy) }\end{array}$ & $\begin{array}{l}\text { Total } \\
\text { Dose } \\
\text { (GY) }\end{array}$ & $\begin{array}{l}\sim \text { BED2Gy } \quad \alpha / \\
\beta=2 G y / 3 G y\end{array}$ & $\%$ BPN [grade] & $\begin{array}{l}\text { Interval to } \\
\text { BPN mean } \\
\text { (range) }\end{array}$ \\
\hline & [33] & 1996 & 1958-1962 & $\begin{array}{l}\text { na (na } \\
2.5)\end{array}$ & 33 & 4.58 & 55 & $90 / 83$ & $73 \%[1-3]$ & $0.5-2.5 y$ \\
\hline & & & & & 84 & 4.25 & 51 & $80 / 74$ & $15 \%[1-3]$ & $0.5-2 y$ \\
\hline & [14] & 1987 & $1980-1983$ & na $($ na -7$)$ & 250 & 3.4 & 51 & $69 / 66$ & $2.4 \%$ [1 and 3$]$ & $0.3-2 y$ \\
\hline \multirow[t]{3}{*}{$\mathrm{H}$} & [31] & 1990 & 1982-1984 & na (3-5.5) & 338 & 3 & 45 & $56 / 54$ & $5.90 \%$ & (1-4 year) \\
\hline & [9] & 1995 & 1981-NA & $\begin{array}{l}\text { median } 8 \\
(2-11)\end{array}$ & 113 & 2.67 & 40 & $47 / 46$ & $0 \%$ & 0 \\
\hline & [26] & 1995 & 1981-NA & $\begin{array}{l}\text { median } 8 \\
(1-11)\end{array}$ & 334 & 2.67 & 40 & $47 / 46$ & $0 \%$ & 0 \\
\hline \multirow[t]{3}{*}{$\mathrm{Y}$} & [32] & 1997 & 1979-1986 & $\begin{array}{l}\text { median } \\
12.5 \text { (na) }\end{array}$ & 164 & 2.19 & 35 & $37 / 36$ & $0 \%$ & 0 \\
\hline & [29] & 2000 & 1963-1965 & $($ na - 34) & 71 & 4 & 44 & $66 / 62$ & $63 \%[1-4]$ & $\begin{array}{l}4.2 y(<1-19 \\
y\end{array}$ \\
\hline & [24] & 2000 & 1989-1992 & $\begin{array}{l}\text { alive: } \\
\text { median } \\
5.9 \text { (na } \\
10)\end{array}$ & 1148 & 2.66 & 40 & $47 / 46$ & $0 \%$ & 0 \\
\hline \multirow[t]{3}{*}{$\mathrm{P}$} & {$[27]^{*}$} & 2002 & 1984-1999 & $($ na - 10) & 89 & 6 & 30 & $60 / 55$ & $0 \%[2-4]$ & 0 \\
\hline & [25] & 2004 & 1980-1993 & $\begin{array}{l}\text { median } \\
7.3 \\
(2.5-18)\end{array}$ & 332 & 2.6 & 52 & $60 / 58$ & $14 \%[1-4]$ & $\begin{array}{l}>1=G 3: \\
0.8 \% / y\end{array}$ \\
\hline & [1] & 2008 & 1999-2002 & $\begin{array}{l}\text { median } \\
5.1 \text { (max. } \\
8.0)\end{array}$ & 119 & 3.2 & 42 & $54 / 52$ & $0.1 \%[1]$ & $2 y$ \\
\hline $\mathrm{O}$ & [2] & 2008 & 1999-2001 & $\begin{array}{l}\text { median } 6 \\
(\max .8 .0)\end{array}$ & 74 & 2.67 & 40 & $47 / 46$ & 0 & 0 \\
\hline
\end{tabular}

The strength of the analysis lays in its long follow up time period of a relatively large sample size of patients treated with a homogeneous radiation regimen applied during one decade in a single institution, as well as in the regular clinical long term follow up at the same department (Table 1).

Regarding the BPN scoring, there is, to our knowledge, no specific standard available. Olsen et al. [13] defined a three-step grading, with 'disabling BPN in daily life' as grade 1: presence of disabling sensory disturbances, weakness, atrophy or hypoactivity of muscle stretch reflexes), 'mild BPN' as grade 2: all of grade 1, but mild), and grade 3: no BPN (absence of neurological signs and symptoms). Bajrovic et al. graded BPN using a modified LENT-SOMA four-step score [24], while we grouped symptoms to a three-step scale with emphasis on the functional aspect (see 'methods'); our grade 3 compares to the grades 3 and 4 in Bajrovic et al. and Olsen et al. grade 1, respectively.

A few papers describe rare instances of plexus lesions after a dose of $50 \mathrm{~Gy}$ with $2 \mathrm{~Gy} /$ fraction or $45 \mathrm{~Gy}$ with $2.25 \mathrm{~Gy} /$ fraction. Listed in Table 3 are selected published data on the rate of brachial plexus neuropathy (BPN) following differently fractionated radiation therapy of the breast and axillary \pm supraclavicular regionpublished in the literature $[1-3,9,13,14,25-33]$, showing a low rate of high grade BPN, comparable as following normal-fractionation. 
Page 7 of 8

\begin{tabular}{|c|c|c|c|c|c|c|c|c|c|c|}
\hline & [3] & 2013 & 1999-2002 & $\begin{array}{l}\text { median } \\
9.3 \text { (max. } \\
12.4)\end{array}$ & 193 & 3.20 or 2.67 & $41.6 / 40$ & $54 / 52 ; 47 / 46$ & $\begin{array}{l}\text { none } \\
\text { mentioned }\end{array}$ & 0 \\
\hline & own study & 2014 & $1967-1977$ & $\begin{array}{l}\text { median } \\
26.6 \\
(7-45.2)\end{array}$ & 124 & 3.3 & 43 & $56 / 54$ & $1 \%[2]$ & $25 y$ \\
\hline & [30] & 1992 & 19968-1985 & $\begin{array}{l}\text { median } \\
6.6 \\
(<1-19)\end{array}$ & 1117 & 2 & 50 & 50 & $1.8 \%[1-2]$ & $\begin{array}{l}10 \text { months } \\
(1.5-77)\end{array}$ \\
\hline $\mathrm{N}$ & [13] & 1993 & $1982-1990$ & median 4 & 128 & 2 & & 50 & $9 \% / 5 \%[1 / 3$ & no latency \\
\hline $\mathrm{O}$ & [31] & 1990 & 1982-1984 & $(3-5.5)$ & 111 & 1.8 & 54 & 51 & $1 \%$ [?] & (1-4 years) \\
\hline $\mathrm{R}$ & [28] & 1990 & 1977-1985 & median 10 & 697 & 2 & 50 & 50 & $<1 \%$ [na] & na \\
\hline M & [1] & 2008 & 1999-2002 & $\begin{array}{l}\text { median } \\
5.1 \text { (max. } \\
8.0)\end{array}$ & 309 & 2 & 50 & 50 & $0 \%$ & 0 \\
\hline \multirow[t]{2}{*}{0} & [2] & 2008 & 1999-2001 & $\begin{array}{l}\text { median } 6 \\
(\max .8 .0)\end{array}$ & 153 & 2 & 50 & 50 & $0 \%$ & 0 \\
\hline & [3] & 2013 & 1999-2002 & $\begin{array}{l}\text { median } \\
9.3 \text { (max. } \\
12.4)\end{array}$ & 462 & 2 & 50 & 50 & $\begin{array}{l}\text { none } \\
\text { mentioned }\end{array}$ & 0 \\
\hline
\end{tabular}

Table 3: Selected published data on the rate of brachial plexus neuropathy (BPN) following differently fractionated radiation therapy of the breast and axillary \pm supraclavicular region.

*: postoperative axillary radiation after axillary melanoma metastasis dissection, 2 fractions/week.

START A/B: no information available regarding axillary vs. supraclavicular vs. axillary and supraclavicular treatment volumes.

According to an analysis included in the protocol of the START A trial, at least in some of those patients the dose per fraction, the total dose and the dose to the plexus were higher than the prescription dose. This was also the case in our patient who developed grade 2 PBN (see 'method'). With the same relevance is the published decade long experience of supraclavicular and axillary irradiation with 40Gy in 15 fractions [24].

For our historic group radiated with $3.3 \mathrm{~Gy}$ to the midline dose in 13 fractions, we re-calculated the dose distribution based on the planning CT of actual patients treated for breast cancer (Figures 2 and 3), the range of DVHs in this historic cobalt group includes very well the $\mathrm{DVH}$ of an equally weighted photon $6 \mathrm{MV}$ opposed field applying the dose of 13 fractions with $3.2 \mathrm{~Gy}$ used in one of the arms of the START A trial.

Considering published results on the incidence and risk of various radiation regimes for brachial plexus lesions-including own results-, we come to the following conclusions:

The results from our historic group corroborate that a hypo fractionated regime as used in the START A and B trials as well as in the related pilot trials, and not exceeding the dose limits as listed in the START protocol (START A Trial Final Protocol; Standardisation of Breast Radiotherapy, July $1998[13,30]$ ), is as safe as applying 25 fractions with $2.0 \mathrm{~Gy}$ target dose.

The results from our historic group corroborate the results in the START protocol (START A Trial Final Protocol; Standardisation of Breast Radiotherapy, July 1998): 'It seems reasonable to assume that an absorbed dose equivalent to $50 \mathrm{~Gy}$ in $2 \mathrm{~Gy}$ fractions at the level of the brachial plexus is safe in the absence of axillary surgery or chemotherapy. 'Safe' means a risk of radiation-induced BPN much lower $(<1 \%)$ than the risk of malignant BPN were no radiotherapy to be given'.

The results of the Christie Hospital in Manchester based on $>2000$ patients [24] treated with a regime of between 40 and 42Gy in 15 or 16 fractions also supports this conclusion.

\section{Conclusion}

The long term follow up in our patients corroborates the hypothesis of a total mid plane dose in the supraclavicular/axillary region between $40-42 \mathrm{~Gy}$ in 13 fractions being comparably safe as the normo fractionated regimen using $25 \times 2.0 \mathrm{~Gy}$ to $50 \mathrm{~Gy}$.

\section{Acknowledgement}

We like to acknowledge Mr. Hansruedi Hohler for his great support in collecting patient charts/portal films/simulation films and follow up information from the assessed historic cohort treated in the period of 1967-1977.

\section{References}

1. Yarnold J and the START Trialists' Group (2008)The UK Standardisation of Breast Radiotherapy (START) Trial A of radiotherapy hypofractionation for treatment of early breast cancer: a randomised trial. Lancet Oncol 9: 331-341.

2. START Trialists' Group, Bentzen SM, Agrawal RK, Aird EG, Barrett JM, et al. (2008) The UK Standardisation of Breast Radiotherapy (START) Trial B of radiotherapy hypofractionation for treatment of early breast cancer: a randomised trial. Lancet 371: 1098-1107.

3. Haviland JS, Owen JR, Dewar JA, Agrawal RK, Barrett J, et al. (2013) The UK Standardisation of Breast Radiotherapy (START) trials of radiotherapy hypofractionation for treatment of early breast cancer: 10- 
year follow-up results of two randomised controlled trials. Lancet Oncol 14: 1086-1094.

4. Owen JR, Ashton A, Bliss JM, Homewood J, Harper C, et al. (2006) Effect of radiotherapy fraction size on tumour control in patients with earlystage breast cancer after local tumour excision: long-term results of a randomised trial. Lancet Oncol 7: 467-471.

5. Whelan TJ, Pignol JP, Levine MN, Julian JA, MacKenzie R, et al. (2010) Long-term results of hypo fractionated radiation therapy for breast cancer. N Engl J Med 362: 513-520.

6. Yarnold J, Bentzen SM, Coles C, Haviland J (2011) Hypo fractionated whole-breast radiotherapy for women with early breast cancer: myths and realities. Int J RadiatOncol Biol Phys 79: 1-9.

7. Owen-Smith A, Coast J, Donovan J (2010) The usefulness of NICE guidance in practice: different perspectives of managers, clinicians, and patients. Int J Technol Assess Health Care 26: 317-322.

8. McBain CA, Young EA, Swindell R, Magee B, Stewart AL (2003) Local recurrence of breast cancer following surgery and radiotherapy: incidence and outcome. Clin Oncol (R CollRadiol) 15: 25-31.

9. Olivotto IA, Weir LM, Kim-Sing C, Bajdik CD, Trevisan CH, et al. (1996) Late cosmetic results of short fractionation for breast conservation. Radiother Oncol 41: 7-13.

10. Romestaing $\mathrm{P}$, Lehingue $\mathrm{Y}$, Carrie $\mathrm{C}$, Coquard R, Montbarbon $\mathrm{X}$, et al. (1997) Role of a 10-Gy boost in the conservative treatment of early breast cancer: results of a randomized clinical trial in Lyon, France. J ClinOncol 15: 963-968.

11. Souchon R, Feyer P, Sautter-Bihl ML, Budach W, Dunst J, et al. (2010) Adjuvanteperkutane hypo (hf)- vs. normofraktionierte (nf) Radiotherapie (RT) der Brustnachorganerhaltender Operation (WBI) wegen Mammakarzinom- für welche Patientinnen ist dieser Ansatz als gleichwertig gesichert? Eine Bewertung der DEGRO Organgruppe Mammakarzinom. Strahlenther Onkol 186 (Sondernr 1): 35.

12. Wiernik G, Bleehen NM, Brindle J, Bullimore J, Churchill-Davidson IF, et al. (1978) Sixth interim progress report of the British Institute of Radiology fractionation study of $3 \mathrm{~F} /$ week versus $5 \mathrm{~F} /$ week in radiotherapy of the laryngo-pharynx. Br J Radiol 51: 241-250.

13. Olsen NK, Pfeiffer P, Johannsen L, Schrøder H, Rose C (1993) Radiationinduced brachial plexopathy: neurological follow-up in 161 recurrencefree breast cancer patients. Int J Radiat Oncol BiolPhys 26: 43-49.

14. Barr LC, Kissin MW (1987) Radiation-induced brachial plexus neuropathy following breast conservation and radical radiotherapy. $\mathrm{Br} \mathrm{J}$ Surg 74: 855-856.

15. Fehlauer F, Tribius S, Alberti W, Rades D (2005) Late effects and cosmetic results of conventional versus hypo fractionated irradiation in breast-conserving therapy. StrahlentherOnkol 181: 625-631.

16. Hoeller U, Bonacker M, Bajrovic A, Alberti W, Adam G (2004) Radiation-induced plexopathy and fibrosis. Is magnetic resonance imaging the adequate diagnostic tool? StrahlentherOnkol 180: 650-654.

17. Platteaux N, Dirix P, Hermans R, Nuyts S (2010) Brachial plexopathy after chemoradiotherapy for head and neck squamous cell carcinoma. StrahlentherOnkol 186: 517-520.

18. Dahlke S, Janssen S, Meyer A, Karstens JH, Bremer M, et al. (2010) Alleinige hypofraktionierte Bestrahlung bei Patienten mit fortgeschrittenen Kopf-Hals-Tumoren. Strahlenther Onkol186 (Sondernr 1): 135 .
19. Dumke Ak, Pelz T, Vondermark D (2010) Ergebnisse der Radiotherapie beim anaplastischen Schilddrüsenkarzinom. Strahlenther Onkol186 (Sondernr 1): 129.

20. Brar P, Jain S, Singh I (2011) Complications of Axillary Lymph Node Dissection in Treatment of Early Breast Cancer: A Comparison of MRM and BCS. Indian J Surg Oncol 2: 126-132.

21. Liljegren G, Holmberg L (1997) Arm morbidity after sector resection and axillary dissection with or without postoperative radiotherapy in breast cancer stage I. Results from a randomised trial. Uppsala-Orebro Breast Cancer Study Group. Eur J Cancer 33: 193-199.

22. Fleissig A, Fallowfield LJ, Langridge CI, Johnson L, Newcombe RG, et al. (2006) Post-operative arm morbidity and quality of life. Results of the ALMANAC randomised trial comparing sentinel node biopsy with standard axillary treatment in the management of patients with early breast cancer. Breast Cancer Research and Treatment 95: 279-293.

23. Engel J, Kerr J, Schlesinger-Raab A, Sauer H, Hölzel D (2003) Axilla surgery severely affects quality of life: results of a 5 -year prospective study in breast cancer patients. Breast Cancer Res Treat 79: 47-57.

24. Livsey JE, Magee B, Stewart AL, Swindell R (2000) Axillary recurrence following conservative surgery and radiotherapy in early breast cancer. ClinOncol (R Coll Radiol) 12: 309-314.

25. Bajrovic A, Rades D, Fehlauer F, Tribius S, Hoeller U, et al. (2004) Is there a life-long risk of brachial plexopathy after radiotherapy of supraclavicular lymph nodes in breast cancer patients? Radiother Oncol 71: $297-301$

26. Ash DV, Benson EA, Sainsbury JR, Round C, Head C. (1995) Seven-year follow-up on 334 patients treated by breast conserving surgery and short course radical postoperative radiotherapy: a report of the Yorkshire Breast Cancer Group. ClinOncol (R Coll Radiol)7: 93-96.

27. Ballo MT, Strom EA, Zagars GK, Bedikian AY, Prieto VG, et al. (2002) Adjuvant irradiation for axillary metastases from malignant melanoma. Int J Radiat Oncol Biol Phys 52: 964-972.

28. Fowble BL, Solin LJ, Schultz DJ, Goodman RL (1991) Ten year results of conservative surgery and irradiation for stage I and II breast cancer. Int J Radiat Oncol Biol Phys 21: 269-277.

29. Johansson S, Svensson H, Denekamp J (2000) Timescale of evolution of late radiation injury after postoperative radiotherapy of breast cancer patients. Int J Radiat Oncol Biol Phys 48: 745-750.

30. Pierce SM, Recht A, Lingos TI, Abner A, Vicini F, et al. (1992) Long-term radiation complications following conservative surgery (CS) and radiation therapy (RT) in patients with early stage breast cancer. Int J Radiat Oncol Biol Phys 23: 915-923.

31. Powell S, Cooke J, Parsons C (1990) Radiation-induced brachial plexus injury: follow-up of two different fractionation schedules. Radiother Oncol 18: 213-220.

32. Ragaz J, Jackson SM, Le N, Plenderleith IH, Spinelli JJ, et al. (1997) Adjuvant radiotherapy and chemotherapy in node-positive premenopausal women with breast cancer. N Engl J Med 337: 956-962.

33. Stoll BA, Andrews JT (1966) Radiation-induced Peripheral Neuropathy. Br Med J 1: 834-837.
This article was originally published in a special issue, entitled: "Cancer Radiation Therapy", Edited by Xin Chen,University of Arkansas for Medical Sciences, USA 